\title{
Incidence of childhood-onset bipolar illness in the USA and Europe
}

Robert M. Post, David A. Luckenbaugh, Gabriele S. Leverich, Lori L. Altshuler, Mark A. Frye, Trisha Suppes, Paul E. Keck, Susan L. McElroy, Willem A. Nolen, Ralph Kupka, Heinz Grunze, and Joerg Walden

\section{Summary}

The relative incidence of childhood-onset bipolar illness in the USA compared with that in Europe is controversial. We examined this issue in more than 500 out-patients (average age 42 years) with bipolar illness who reported age at onset of first episode, family history, and childhood physical or sexual abuse. Childhood or adolescent onset of bipolar illness was reported by $61 \%$ of those in the US cohort but by only $30 \%$ of those in The Netherlands or Germany. In the USA there was also twice the incidence of childhood adversity and genetic/familial risk for affective disorder. The findings deserve replication and further exploration.

\section{Declaration of interest}

\section{None.}

The data were analysed using SPSS version 14.0.2 for Windows. We used $t$-tests to examine the differences between the USA and Europe on continuous measures and the chi-squared test was used with categorical measures.

\section{Results} In the Bipolar Collaborative Network (BCN) we found 16\% with childhood onset and $50 \%$ had onset prior to age 20 years. ${ }^{7}$ Those with childhood onset had the longest delays to first treatment and showed a more difficult course as reported retrospectively and as rated prospectively. ${ }^{7}$

Three of the seven sites in the BCN were in Europe (Utrecht, The Netherlands; Freiburg and Munich, Germany). Four were in the USA: Los Angeles, Dallas, Cincinnati and Bethesda. We therefore had the opportunity to assess possible differences in age at onset and associated vulnerability factors using data emanating from the US compared with the European centres.

\section{Method}

All patients gave oral and written informed consent to participate. ${ }^{5,8,9}$ Representative out-patients were recruited at each site as there were no exclusion criteria except major medical infirmity or active substance misuse requiring treatment elsewhere.

Patients were formally diagnosed using the Structured Clinical Interview for DSM-IV Axis I disorder (SCID) $;^{10}$ and they completed questionnaires about the nature and extent of their prior course of illness. ${ }^{8}$ The 543 patients were an average age of approximately 42 years at Network entry, with a mean of about 20 years of prior illness. To establish the age at onset of the first depression, patients were asked about their first depressive symptoms associated with dysfunction (i.e. a definition that would be likely to meet DSM-IV criteria), as well as their first hypomanic or manic symptoms (similar to those experienced in adulthood). In addition, the age of first psychopharmacological treatment for either mania or depression was recorded, as was a family history of psychiatric illness in first-degree relatives. In this cohort 337 patients had data on the age at onset of illness based on SCID interview which highly correlated with self-report $(r=0.80)$. Age at onset was divided as in the study of Perlis and colleagues; ${ }^{2}$ see Fig. 1.
Only $2 \%$ of patients had childhood-onset bipolar disorder in the three European sites (Fig. 1), compared with $22 \%$ in the four US sites $(t=6.84$, d.f. $=591, P<0.0001)$. This was reflected in the higher mean age at onset of illness of 25.2 years $($ s.d. $=9.9)$ for the European sites $v$. 19.4 years (s.d.=9.7) for the US sites. Age at onset and duration of the untreated interval ${ }^{5}$ were inversely correlated ( $r=-0.46, P<0.0001)$, so the period of delay from onset to first treatment was shorter in the patients from Europe (4.7 years, s.d.=6.6) than in those from the USA (10.9 years, s.d. $=10.6 ; t=6.99$, d.f. $=468, P<0.0001)$.

In examining possible risk factors, the US sample compared with the European sample had a significantly $(P<0.001)$ higher incidence of a positive family history of bipolar disorder $(51 \%$ v. $24 \%)$, major depressive disorder $(63 \%$ v. $44 \%)$ and actual or attempted suicide (36\% v. 19\%), and of childhood physical $(30 \% v .14 \%)$ and sexual $(30 \%$ v. 17\%) abuse. These differences

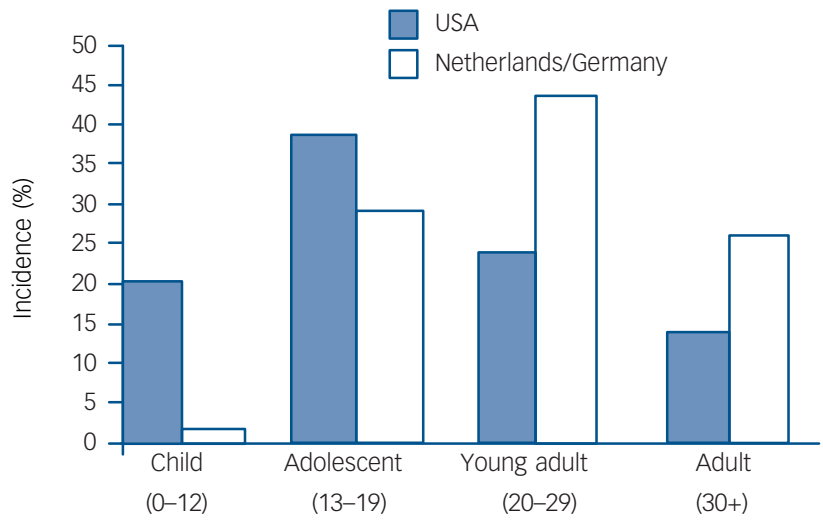

Age at onset (years)

Fig. 1 Age at onset of bipolar disorder: comparison of US and European samples. 
remained significant $(P<0.01)$ whether or not all participants with childhood-onset disorder were eliminated from the analysis.

Compared with the European patients, US patients also had a higher $(P<0.001)$ incidence of rapid cycling $(58 \%$ v. $37 \%)$, dysphoric mania $(67 \% v .41 \%)$ and comorbid substance misuse (47\% vs $27 \%$ ). Only a history of psychosis was more prevalent in the European cohort (66\%) than in the US cohort (53\%). Current age at Network entry, gender and age at onset of first treatment and hospitalisation were not different.

\section{Discussion}

Our finding indicating that $61 \%$ of the US patients had their onset of bipolar disorder prior to age 19 years - double the rate for the European sites (30\%) - is highly similar to the $66 \%$ figure reported by Perlis and colleagues ${ }^{2}$ or the $59 \%$ prior to age 20 years reported by Lish and colleagues, ${ }^{1}$ both studies that recruited patients exclusively in the USA.

A critical issue is whether this apparent incidence differential could be an artefact of recruitment bias, healthcare availability or variations in interpretation of the same questions by the patient or interviewer. However, at all sites patients were recruited almost exclusively from out-patient clinics and advertisements, and the average age and a variety of demographic variables, including gender and marital status, did not differ between the US and European sites. Whether the SCID clinician interview data or self-rated data were used, the distributions in the USA $v$. Europe remained very different.

Retrospective assessments of age at onset of illness by SCID interview or self-report (although highly correlated) are both subject to errors in judgement and recall, and are probably more difficult for early episodes. However, there is little reason to suspect that these errors would occur differentially in Europe and the USA. Moreover, these retrospective data regarding differential age at onset appear to be paralleled by prospective cross-sectional evaluation of childhood clinical psychiatric populations ${ }^{4,6}$ and in those at high risk..$^{11,12}$

Finally, the highly significant increase in both familial/genetic and psychosocial adversity risk factors in the USA compared with The Netherlands and Germany to some extent indirectly internally validates the age at onset data and is consistent with the wellreplicated prospective reports of a high familial loading in childhoodonset bipolar illness cohorts. ${ }^{4}$ Nevertheless, questions about the differential incidence and the generality to other European countries ${ }^{13}$ can only be definitively answered by large-scale epidemiological studies using the same diagnostic instruments.

If these data are valid, clinical and theoretical questions about causes and mechanisms are immediately raised. Explanations of how a greater genetic loading in the USA might occur could include: a higher risk of affective illness in those who migrated from Europe to the USA; increased assortative mating (as seen in our data); faster accumulation of vulnerability genes because of shorter times between reproductive generations; ${ }^{14}$ or differential rates of anticipation. ${ }^{15}$ Environmentally based mechanisms could include an increased incidence of childhood adversity (as observed here); different degrees of psychosocial stress based on culture; environmental toxins; dietary differences; differential treatment of attention-deficit hyperactivity disorder with stimulants; ${ }^{12}$ or an increased rate of substance misuse (as observed).

Whatever the mechanisms, these preliminary findings deserve further exploration and could provide important hints about increased vulnerability factors in the USA and protective factors in some European populations. As such, they could help uncover important variables that could be utilised both in clinical treatment strategies and in public health preventive measures. ${ }^{16}$
Robert M. Post, MD, Department of Psychiatry, George Washington University, Washington, DC, and Penn State College of Medicine, Hershey, Pennsylvania; David A. Luckenbaugh, MA, Gabriele S. Leverich, MSW, Mood and Anxiety Disorder Program, National Institute of Mental Health, Bethesda, Maryland; Lori L. Altshuler MD, University of California, Los Angeles, Mood Disorders Research Program, and VA Medical Center, Los Angeles, California; Mark A. Frye, MD, Department of Medical Center, Los Angeles, California; Mark A. Frye, MD, Department of
Psychiatry, Mayo Clinic, Rochester, Minnesota; Trisha Suppes, MD, PhD, Department of Psychiatry, Southwestern Medical Center, University of Texas, Dallas, Texas; Paul E. Keck, MD, Susan L. McElroy, MD, Biological Psychiatry Program, University of Cincinnati Medical College, Cincinnati, Ohio, USA; Willem A. Nolen, MD, Universitair Medisch Centrum Groningen (UMCG), Groningen; Ralph Kupka, MD, PhD, H.C. Rumke Groep, Willem Arntsz Huis, Utrecht, The Netherlands; Heinz Grunze, MD, Department of Psychiatry, University of Freiburg, Germany; Joerg Walden, MD, Psychiatrische Clinik, Ludwig-Maximilians University, Munich, Germany

Correspondence: Robert M. Post, Bipolar Collaborative Network, 5415 W. Cedar Lane, Suite 201-B Bethesda, MD 20814, USA. Email: Robert.post@speakeasy.net First received 14 Mar 2007, final revision 6 Jul 2007, accepted 15 Aug 2007

\section{Acknowledgements}

We thank the Stanley Medical Research Institute for supporting the acquisition of these data and the Dalio Family Foundation for ongoing support

\section{References}

1 Lish SD, Dime-Meenan S, Whybrow PC, Price, RA, Hirschfeld, RM. The National Depressive and Manic-Depressive Association (NDMDA) survey of bipolar members. J Affect Disord 1994; 31: 281-94.

2 Perlis RH, Miyahara S, Marangell LB, Wisniewski SR, Ostacher M, DelBello $M P$, Bowden $C L$, Sachs GS, Nierenberg AA. Long-term implications of early onset in bipolar disorder: data from the first 1000 participants in The Systematic Treatment Enhancement Program for Bipolar Disorder (STEP-BD). Biol Psychiatry 2004; 55: 875-81.

3 Kessler RC, Berglund P, Demler O, Jin R, Walters EE. Lifetime prevalence and age-of-onset distributions of DSM-IV disorders in the National Comorbidity Survey Replication. Arch Gen Psychiatry 2005; 62: 590-2.

4 Pavuluri MN, Birmaher B, Naylor MW. Pediatric bipolar disorder: a review of the past 10 years. J Am Acad Child Adolesc Psychiatry 2005; 44: 846-71.

5 Leverich GS, Post RM, Keck PE, Altshuler LL, Frye MA, Kupka RW, Nolen WA, Suppes T, McElroy SL, Grunze H, Denicoff K, Moravec MK, Luckenbaugh D. The poor prognosis of childhood onset bipolar disorder: the need for a paradigm shift for earlier recognition and treatment. J Pediatr 2007; 150: 485-90.

6 Soutullo CA, Chang KD, Diez-Sauarez A, Figueroa-Quintana A, EscamillaCanales I, Rapado-Castro M, Ortuño F. Bipolar disorder in children and adolescents. International perspective on epidemiology and phenomenology. Bipolar Disord 2005; 7: 497-506.

7 Leverich GS, Post RM. Course of bipolar illness after history of childhood trauma. Lancet 2006; 367: 1040-2.

8 Post RM, Nolen WA, Kupka RW, Denicoff KD, Leverich GS, Keck PE Jr, McElroy SL, Rush AJ, Suppes T, Altshuler LL, Frye MA, Grunze H, Walden J. The Stanley Foundation Bipolar Network: 1. Rationale and methods. $\mathrm{Br} \mathrm{J}$ Psychiatry 2001; 178 (suppl 41): 169-76.

9 Suppes T, Leverich GS, Keck PE, Nolen WA; Denicoff KD, Altshuler LL, McElroy SL, Rush AJ, Kupka R, Frye MA, Bickel M, Post RM. The Stanley Foundation Bipolar Treatment Outcome Network. II. Demographics and illness characteristics of the first 261 patients. J Affect Disord 2001; 67: 45-59.

10 First MB, Spitzer RL, Gibbon M, Williams JBW. Structured Clinical Interview for DSM-IV Axis I Disorders - Patient Edition (Research Version, 2/96 final). Biometrics Research Department, NY State Psychiatric Institute, 1996.

11 Chang KD, Steiner H, Ketter TA. Psychiatric phenomenology of child and adolescent bipolar offspring. J Am Acad Child Adolesc Psychiatry 2000; 39: 453-60.

12 Reichart CG, Nolen WA. Earlier onset of bipolar disorder in children by antidepressants or stimulants? An hypothesis. J Affect Disord 2004; 78: 81-4.

13 Bellivier F, Golmard JL, Henry C, Leboyer M, Schurhoff F. Admixture analysis of age at onset in bipolar I affective disorder. Arch Gen Psychiatry 2001; 58: 510-12.

14 Comings DE. The Gene Bomb. Hope Press, 1995.

15 Lange KJ, McInnis MG. Studies of anticipation in bipolar affective disorder. CNS Spectr 2002; 7: 196-202.

16 Post RM, Kowatch RA. The health care crisis of childhood-onset bipolar illness: some recommendations for its amelioration. J Clin Psychiatry 2006; 67: 115-25. 